\title{
Catechins inhibit angiotensin II-induced vascular smooth muscle cell proliferation via mitogen-activated protein kinase pathway
}

\author{
Sun-Mi Won ${ }^{1}$, Youn-Hee Park', \\ Hee-Jung Kim ${ }^{1}$, Kwon-Moo Park ${ }^{2}$ and \\ Won-Jung Lee ${ }^{1,3}$ \\ ${ }^{1}$ Department of Physiology \\ ${ }^{2}$ Department of Anatomy \\ School of Medicine, Kyungpook National University \\ Daegu 700-422, Korea \\ ${ }^{3}$ Corresponding author: Tel, 82-53-420-4811; \\ Fax, 82-53-424-3349; E-mail, wjleek@knu.ac.kr
}

Accepted 6 September 2006

Abbreviations: Ang II, angiotensin II; AP-1, activator protein-1; EC, epicatechin; ECG, epicatechingallate; EGCG, epigallocatechingallate; ERK, extracellular signal-regulated protein kinase; JNK, c-jun-N-terminal kinase; MAPK, mitogen-activated protein kinases; VSMC, vascular smooth muscle cells

\begin{abstract}
Catechins, components of green tea, reduce the incidence of cardiovascular diseases such as atherosclerosis. Angiotensin II (Ang II) is highly implicated in the proliferation of vascular smooth muscle cells (VSMC), resulting in atherosclerosis. The acting mechanisms of the catechins remain to be defined in the proliferation of VSMC induced by Ang II. Here we report that catechin, epicatechin (EC), epicatechingallate (ECG) or epigallocatechingallate (EGCG) significantly inhibits the Ang II-induced $\left[{ }^{3} \mathrm{H}\right]$ thymidine incorporation into the primary cultured rat aortic VSMC. Ang II increases the phosphorylation of the extracellular signal-regulated protein kinase 1/2 (ERK 1/2), c-jun-N-terminal kinase $1 / 2$ (JNK 1/2), or p38 mitogen-activated protein kinases (MAPKs) and mRNA expression of $\mathrm{c}$-jun and c-fos. The EGCG pretreatment inhibits the Ang II-induced phosphorylation of ERK 1/2, JNK 1/2, or p38 MAPK, and the expression of c-jun or c-fos mRNA. U0126, a MEK inhibitor, SP600125, a JNK inhibitor, or SB203580, a p38 inhibitor, attenuates the Ang II-induced $\left[{ }^{3} \mathrm{H}\right]$ thymidine incorporation into the VSMC. In conclusion, catechins inhibit the Ang II-stimulated VSMC proliferation via the inhibition of the Ang II-stimulated activation of MAPK and
\end{abstract}

activator protein-1 signaling pathways. The antiproliferative effect of catechins may be associated with the reduced risk of cardiovascular diseases by the intake of green tea. Catechins may be useful in the development of prevention and therapeutics of vascular diseases.

Keywords: angiotensin II; catechin; mitogen-activated protein kinase; muscle, smooth, vascular; proto-oncogene proteins c-fos; proto-oncogene proteins c-jun

\section{Introduction}

Hyperplasia and/or hypertrophy of the vascular smooth muscle cells (VSMC) are pivotal factors in cardiovascular diseases such as atherosclerosis (Ross, 1993; Lake and Castellot Jr, 2003). Green tea consumption has been associated with a reduction in the risk of cardiovascular diseases (Weisburger and Chung, 2002). Among the green tea components, the family of catechins such as cathechin, epicatechin (EC), epicatechin-3-gallate (ECG), epigallocatechin (EGC), and epigallocatechin-3-gallate (EGCG) have been known to be involved in the reduction of atherosclerosis (Ikigai et al., 1993), stroke (Uchida et al., 1995), and hypocholesterolemia (Yamaguchi et al., 1991). Recently, it has been reported that EGCG inhibited the proliferation of VSMC (Yokozawa et al., 1995; Cao and Cao, 1999; Zheng et al., 2004), whereas the molecular mechanisms of catechins in the inhibition of the proliferation of VSMC remain to be defined.

Angiotensin II (Ang II) has been strongly implicated in the pathogenesis of hypertension, heart failure and arteriosclerosis characterized by abnormal proliferation and hypertrophy of the VSMC (Berk et al., 1989; Jackson and Schwartz, 1992; Horiuchi et al., 1999). Ang II regulates the activation of mitogenactivated protein kinases (MAPK) which are involved in the regulation of cell growth and division (Davis, 1993; Schmidt-Ott et al., 2000), through AT1 or AT2 receptors (Berk et al., 1989; Duff and Berk, 1995). In the present studies, we determined whether catechins play a role in the Ang II-induced VSMC proliferation and whether the effect of catechins is involved in the MAPK signaling pathways. In the 
present studies we found that catechins suppressed Ang II-induced increases of $\left[{ }^{3} \mathrm{H}\right]$ thymidine incorporation into the VSMC and that EGCG suppressed the Ang II-induced phosphorylation of ERK 1/2, JNK $1 / 2$, and p38 MAP kinases, and the expression of c-jun/c-fos mRNA. We further found that MAPKs inhibitors such as MEK, JNK or p38 inhibitor, inhibited the Ang Il-induced increase of $\left[{ }^{3} \mathrm{H}\right]$ thymidine incorporation into the VSMCs.

\section{Materials and Methods}

\section{Materials}

The following reagents were used: trypsin-EDTA and Trizol reagent (Gibco BRL, Gland Island, NY); SP600125 and U0126 (Calbiochem, San Diego, CA); angiotensin II, EGCG, ECG, EC, catechin, and SB203580 (Sigma, St. Louis, MO); $\left.{ }^{3} \mathrm{H}\right]$ thymidine and enhanced chemiluminescence (ECL kit, Amersharm Pharmacia Biotech, Arlington Heights, IL); Micro BCA protein assay kit (Pierce, Rockford, IL); Reverse transcriptase and dNTPs (Promega, Madisons, WI); Taq polymerase (Roche Molecular System, CA); Phospho-SAPK/JNK, Phospho-p38 MAPK (Thr 180/Thr 182) and p38 MAPK antibodies (Cell signaling Technology, Beverly, MA); PhosphoERK1/2 and total ERK1/2 (Santa Cruz Bio Technology, Inc., Santa Cruz, CA); anti-mouse IgG antibody (Amersham Life Science, Arlington Heights, IL). Plastic ware for the cell culture was purchased from Nunc (Roskilde, Denmark).

\section{Cell culture}

Rat aortic smooth muscle cells were isolated from the thoracic aorta of female Sparque-Dawley rats (10 weeks old) and cultured in Dulbecco's modified Eagles medium (DMEM, Gibco BRL) supplemented with $10 \%$ fetal bovine serum (FBS, Hyclone Laboratory, Logan, UT), penicillin (10 U/ml, Gibco BRL), streptomycin $(10 \mathrm{U} / \mathrm{ml}$, Gibco BRL). The cells of passage 3 to 12 were used. Before treatment with reagents such as Ang II, cells were incubated in phenol red-free DMEM for $48 \mathrm{~h}$ without serum, in order to allow the cells to reach a quiescent state.

\section{DNA synthesis}

The DNA synthesis in VSMC was determined by $\left[{ }^{3} \mathrm{H}\right]$ thymidine incorporation into the cells. Briefly, sub-confluent cells were incubated in $1 \mu \mathrm{Ci}$ of $\left[{ }^{3} \mathrm{H}\right]$ thymidine/well for $4 \mathrm{~h}$ before harvesting the cells. Then, DNA synthesis was measured by the radioactivity incorporated into the tricholoacetic acidinsoluble fraction of the cells, and counted by a $\beta$-counter (Wallac 1409, Finland).

\section{Western blot analysis}

After various treatments, VSMCs were harvested and lysed in a $100 \mu$ lysis buffer $(20 \mathrm{mM}$ Tris- $\mathrm{HCl} \mathrm{pH}$ $8,137 \mathrm{mM} \mathrm{NaCl}, 1 \mathrm{mM} \mathrm{MgCl} 2,1 \mathrm{mM}$ sodium orthovanadate, $1 \%$ Nonidet P-40, $1 \mathrm{mM}$ phenylmethyIsulfonylfluoride, $10 \mu \mathrm{g} / \mathrm{ml}$ leupeptin, $10 \mu \mathrm{g} / \mathrm{ml}$ aprotinin). The lysate was centrifuged at $14,000 \mathrm{~g}$ for 20 min and supernatant was used for Western blot analysis. Protein was resolved by SDS-polyacrylamide gel electrophoresis, and blotted on to a nitrocellulose membrane. The membranes were blocked in 5\% nonfat milk in tris-buffered saline/ $0.1 \%$ Tween-20 for $1 \mathrm{~h}$ at room temperature. Then, the membrane was incubated in anti-phopho ERK1/2, anti-total ERK1/2, anti-phospho p38 MAPK, anti-total p38 MAPK antibody, anti-phospho JNK 1/2 antibody or anti-total JNK 1/2 antibody, followed by incubation for $1 \mathrm{~h}$ with a secondary antibody. Immunoreactive bands were visualized using ECL kit.

\section{Immunoprecipitation and immunoblotting}

For immunoprecipitation, cell lysates were incubated with anti-p38 antibody overnight at $4^{\circ} \mathrm{C}$ and then incubated with $40 \mu \mathrm{l}$ of protein $\mathrm{A} / \mathrm{G}$ plus agarose (Santa Cruz Biotechnology) for $3 \mathrm{~h}$ in a roller system at $4^{\circ} \mathrm{C}$. The beads were washed three times with a $1 \mathrm{ml}$ lysis buffer $(20 \mathrm{mM}$ Tris- $\mathrm{HCl} \mathrm{pH} 8,137 \mathrm{mM}$ $\mathrm{NaCl}, 1 \mathrm{mM} \mathrm{MgCl} 2,1 \mathrm{mM}$ sodium orthovanadate, $1 \%$ Nonidet P-40, $1 \mathrm{mM}$ phenylmethylsulfonylfluo-

Table 1. Primer sequences for c-fos, c-jun and GAPDH.

\begin{tabular}{clcc}
\hline Gene & \multicolumn{1}{c}{ Primer sequence $\left(5^{\prime} \rightarrow 3^{\prime}\right)$} & Size & References \\
\hline c-fos & CCACGACCATGATGTTCTCGGGTT & $1,164 \mathrm{bp}$ & Zheng et al., 2004 \\
& CTTCTCTGACTGCTGCTCACAGGGCTA & & Zheng et al., 2004 \\
c-jun & GAAGTGACCGACTGTTCTATGACT & $1,098 \mathrm{bp}$ & Tso et al., 1985 \\
& TCCCTCTTTGCGTTTGGACTA & & \\
GAPDH & ATCAAATGGGGTGATGCTGGTGCTG & $504 \mathrm{bp}$ & \\
& CAGGTCTCCAGGCGGCATGTCAGTT & & \\
\hline
\end{tabular}


ride, $10 \mu \mathrm{g} / \mathrm{ml}$ leupeptin, $10 \mu \mathrm{g} / \mathrm{ml}$ aprotinin) and then equivalent amount of the immune complexes were subjected to electrophoresis on an $10 \%$ SDS polyacrylamide gel and electrotransferred to nitrocellulose membrane. The membrane was treated

$\mathbf{A}$

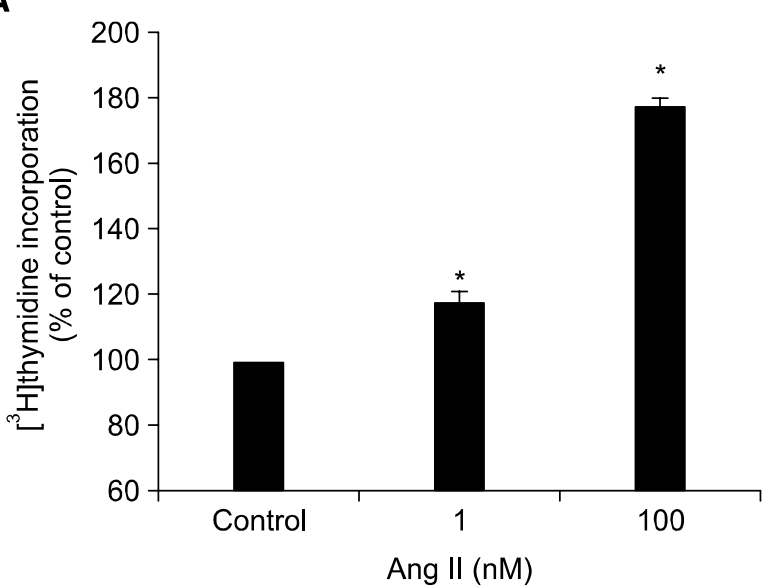

C

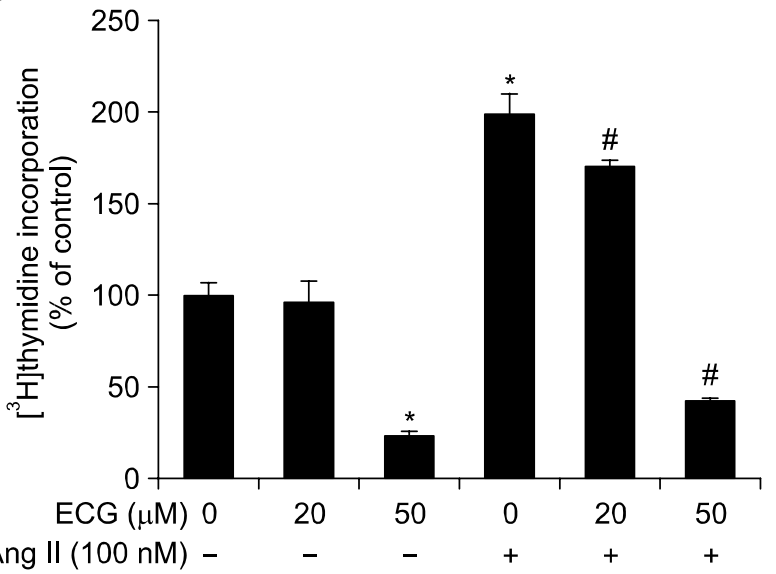

E

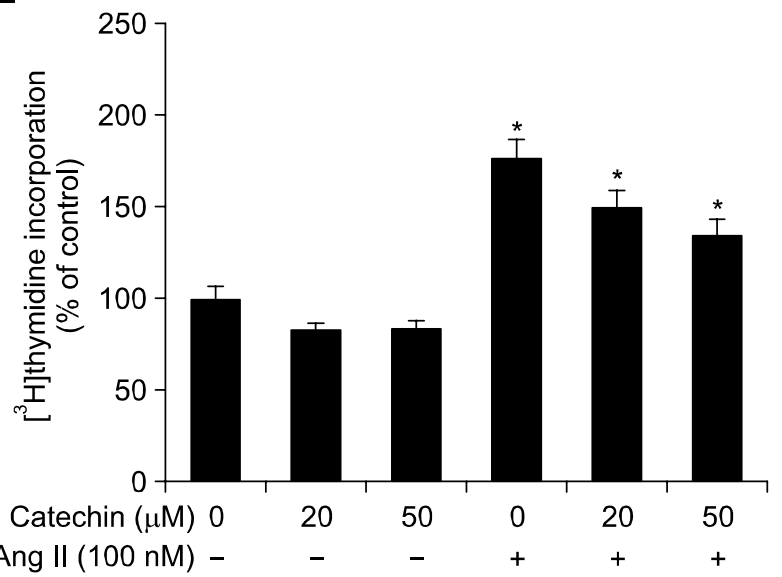

with a blocking buffer at room temperature for $1 \mathrm{~h}$. The membrane was proved with anti-phospho-p38 antibody at $4^{\circ} \mathrm{C}$ overnight and then with a horseradish peroxidase-conjugated goat anti-mouse Ig $\mathrm{G}$ for $1 \mathrm{~h}$. Proteins were visualized on the $\mathrm{X}$-ray film

B

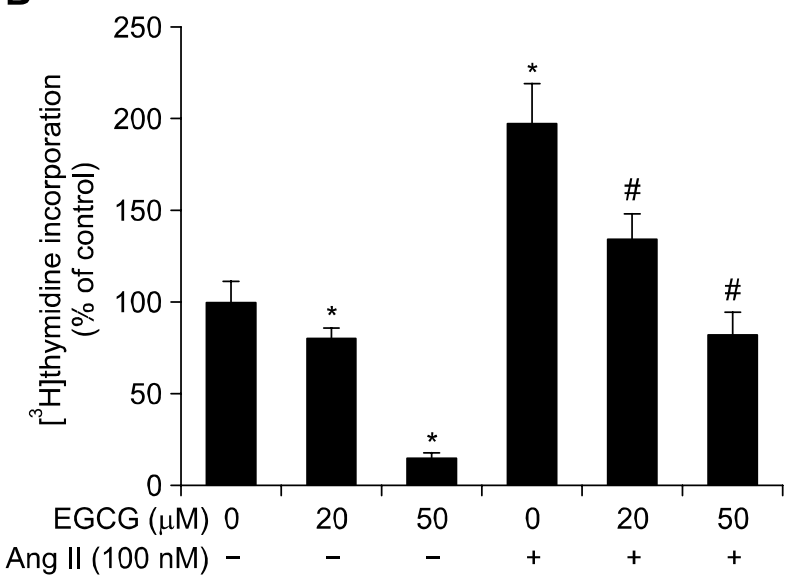

D

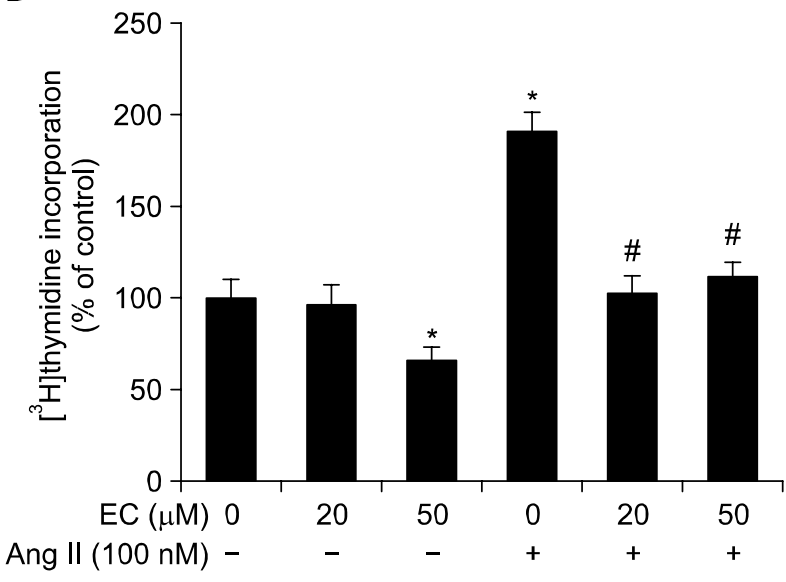

Figure 1. Effect of catechins on angiotensin II (Ang II)-induced $\left[{ }^{3} \mathrm{H}\right]$ thymidine incorporation into the primary cultured aortic vascular smooth muscle cells (VSMC). The VSMC were grown in a $10 \%$ FBS in DMEM. Forty-eight $h$ before using the experiments, the cells were incubated in a $0.5 \%$ FBS in DMEM. In order to determine DNA synthesis cells were treated with $1 \mu \mathrm{Ci}$ of $\left[{ }^{3} \mathrm{H}\right]$ thymidine for $4 \mathrm{~h}$ and then harvested to measure radioactivity using a $\beta$-counter. (A) Some cells were treated with either vehicle (control), or 1 or $100 \mathrm{nM}$ of Ang II for $20 \mathrm{~h}$ before the treatment of $\left[{ }^{3} \mathrm{H}\right]$ thymidine. (B-E) Some cells were treated with epigallocatechin-3-gallate (EGCG), epicatechin-3-gallate (ECG), epicatechin (EC), or catechin 30 min before the treatment with $100 \mathrm{nM}$ of Ang II. In the absence of Ang II, some cells were treated with either vehicle, or 20 or $50 \mu \mathrm{M}$ of EGCG, ECG, EC, or catechin for $20 \mathrm{~h}$. DNA synthesis was assayed by measuring $\left[{ }^{3} \mathrm{H}\right]$ thymidine incorporation. Experiments were performed in triplicate or quadruplicate with the VSMC. Values are means \pm SEM. ${ }^{*}, P<0.01$ compared with their respective control with either the absence or the presence of Ang II, respectively. 
using an ECL Western blotting detection system.

\section{Reverse transcription-polymerase chain reaction}

The expression of c-jun or c-fos mRNA was analyzed by a reverse transcription-polymerase chain

A
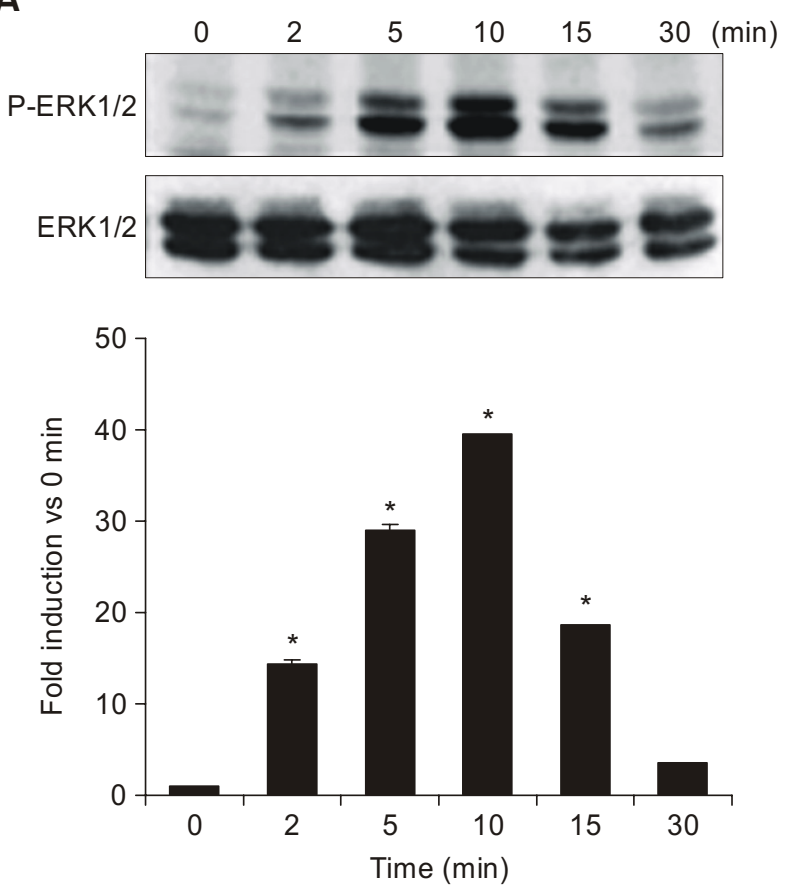

C
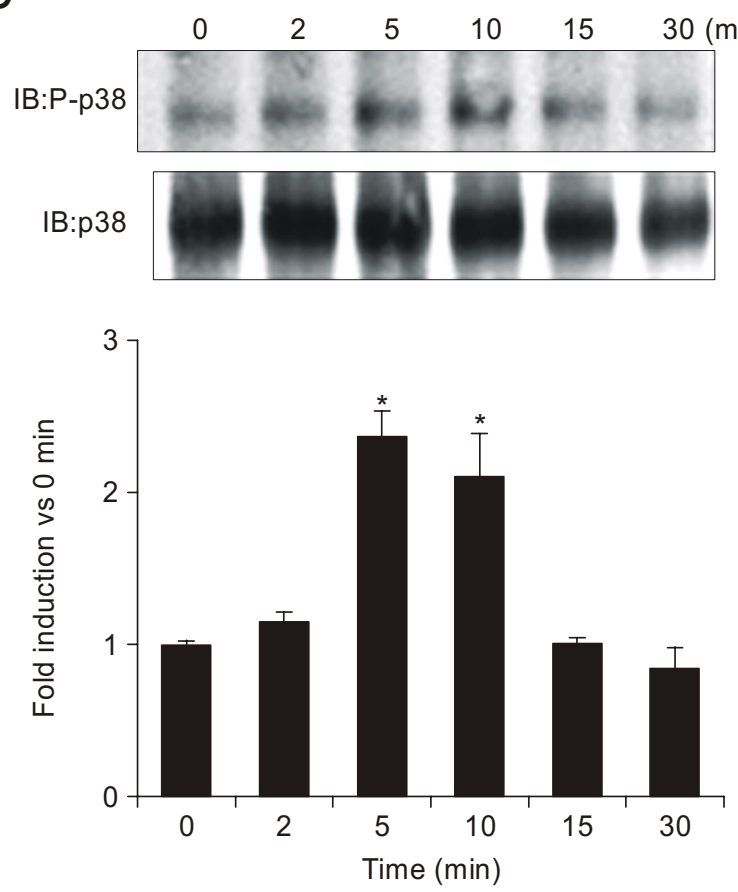

reaction (RT-PCR). Total RNA from the cells was isolated using Trizol RNA isolate kit according to the manufacturer's instructions. Ten $\mu \mathrm{g}$ of RNA were reverse transcribed by oligo (dT) 15 primer and $M-M L V$ reverse transcriptase for $90 \mathrm{~min}$ at $37^{\circ} \mathrm{C}$. The resulting $(5-8 \mu \mathrm{l}) \mathrm{cDNA}$ fragments were amplified by

B
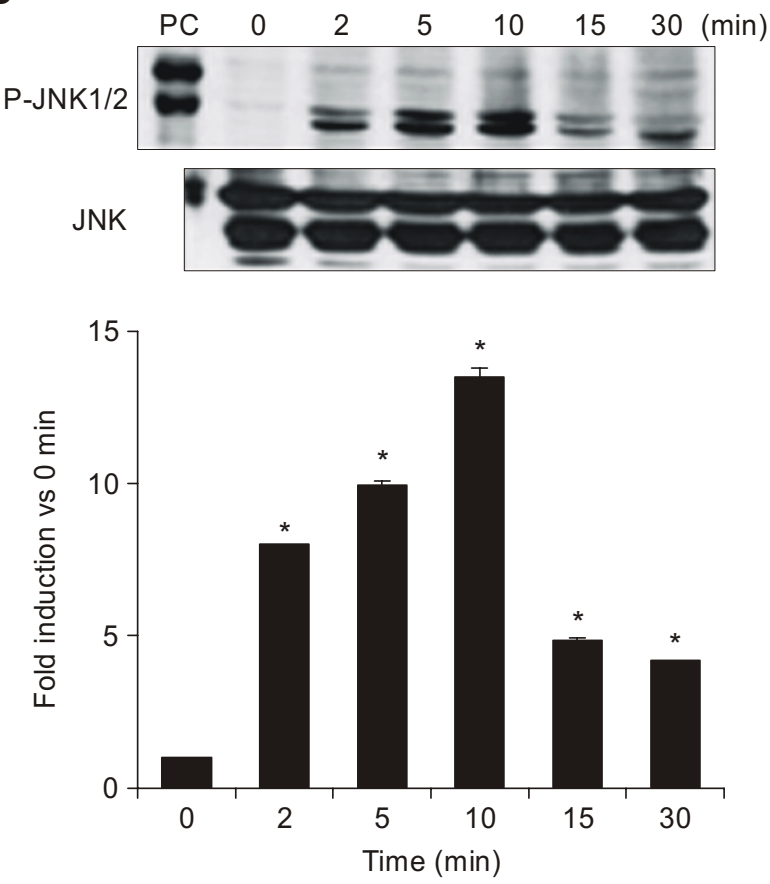

Figure 2. Effect of angiotensin II (Ang II) on ERK1/2, JNK1/2 and p38 phosphorylation in the primary cultured vascular smooth muscle cells (VSMC). The VSMC were grown in a 10\% FBS in DMEM. Forty-eight $\mathrm{h}$ before using the experiments, the cells was incubated in a $0.5 \%$ FBS in DMEM. Some cells were treated with $100 \mathrm{nM}$ of Ang II for indicated times. The phosphorylation of ERK $1 / 2(A)$ and JNK1/2 (B) was measured by Western blot analysis using anti-phospho- ERK $1 / 2$ and JNK1/2 antibodies. To determine the phosphorylation of p38 (C), cell lysates were immunoprecipitated with anti-p38 antibody and then applied for Western blot analysis as described in Materials and Methods. The density of bands was quantified by the NIH Image program. Values presented are expressed as mean \pm SEM $(n=4) .{ }^{*}, P<0.01$ compared with their respective controls. 
PCR. The amplification reaction mixture was $50 \mu$ of total volume, consist of 5-8 $\mu$ l of cDNA, $5 \mu$ of $10 \times$ PCR buffer (100 mM Tris- $\mathrm{HCl} \mathrm{pH} 8.8,15-20 \mathrm{mM}$ $\mathrm{MgCl}_{2}, 500 \mathrm{mM} \mathrm{KCl}, 1 \%$ Triton X-100), $1 \mu$ of $10 \mathrm{nM}$ dNTPs, $0.5 \mu$ of $50 \mathrm{pM}$ oligonucleotide primer set (Table 1), $0.5 \mu \mathrm{l}(1 \mathrm{U})$ of Taq polymerase. The reactions for $\mathrm{c}$-jun and $\mathrm{c}$-fos were performed 32 cycles (denaturation at $95^{\circ} \mathrm{C}$ for $60 \mathrm{~s}$, annealing at $50^{\circ} \mathrm{C}$ for $60 \mathrm{~s}$, and polymerization at $74^{\circ} \mathrm{C}$ for $90 \mathrm{~s}$ ). The mRNA expression of glyceraldehyde-3-phosphate dehydrogenase (GAPDH) was used as internal control for RNA equal loading. The reactions for GAPDH were performed 20 cycles (denaturation at $95^{\circ} \mathrm{C}$ for $1 \mathrm{~min}$, annealing at $56^{\circ} \mathrm{C}$ for $1 \mathrm{~min}$, polymerization at $74^{\circ} \mathrm{C}$ for $90 \mathrm{~s}$ ). The PCR products $(40 \mu \mathrm{l})$ were separated by electrophoresis on $1 \%$ agarose gels and the bands were visualized by ethidium bromide staining under UV illumination.

\section{Statistical analysis}

All growth experiments were performed in triplicate or quadruplicate with aortic VSMCs. Values are expressed as mean \pm SEM. Statistical significance was determined by Students' $t$-tests. A value of $P<$

A
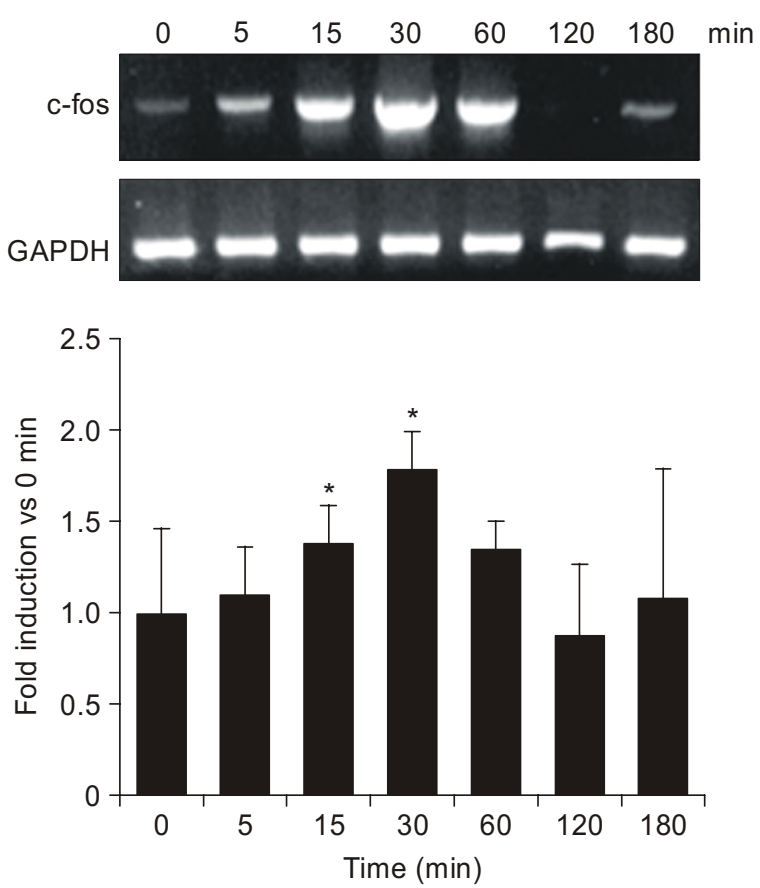

0.01 was considered statistically significant.

\section{Results}

\section{Effect of catechins on Ang Il-induced DNA synthesis in the primary cultured VSMCs}

Ang II increased $\left[{ }^{3} \mathrm{H}\right]$ thymidine incorporation into the VSMCs in a concentration-dependent manner (Figure 1A). Twenty and $50 \mu \mathrm{M}$ of EGCG, ECG or $\mathrm{EC}$, or $50 \mu \mathrm{M}$ of catechin significantly inhibited the Ang Il-stimulated $\left[{ }^{3} \mathrm{H}\right]$ thymidine incorporation (Figure 1B-E). The inhibitory effect of catechins on the Ang II-stimulated proliferation of the VSMC was ECG

$E G C G>E C>C$ at $50 \mu \mathrm{M}$ of catechins and EC > EGCG > ECG or at $20 \mu \mathrm{M}$. In the absence of Ang II, with an exception of catechin, $20 \mu \mathrm{M}$ of EGCG or 50 $\mu \mathrm{M}$ of $E C G$ and EC significantly decreased the $\left.{ }^{3} \mathrm{H}\right]$ thymidine incorporation.

\section{Effect of Ang II on the phosphorylation of MAPKs or expression of c-fos and c-jun mRNA in the VSMCs}

Since MAPKs signaling pathways have been highly implicated in cell proliferation (Davis, 1993; Schmidt-

B
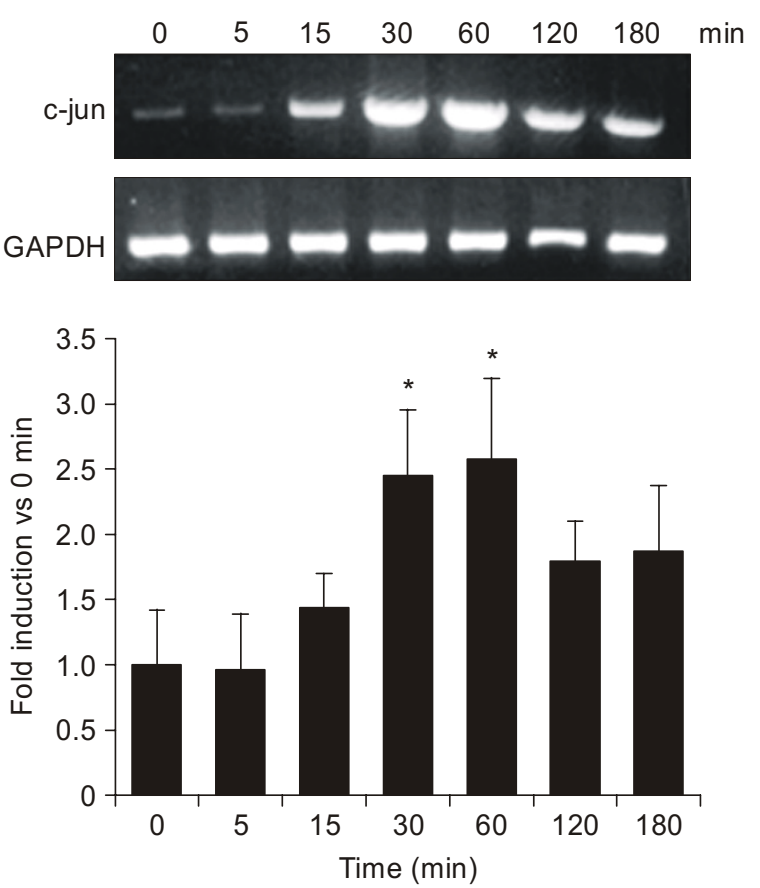

Figure 3. Effect of angiotensin II (Ang II) on both the expression of mRNA of c-fos (A) and c-jun (B) in the primary cultured vascular smooth muscle cells (VSMC). The VSMCs were grown in a 10\% FBS in DMEM. Forty-eight $h$ before using the experiments, the cells were incubated in a $0.5 \%$ FBS in DMEM. Some cells were treated with $100 \mathrm{nM}$ of Ang $I I$ for the indicated times and the total RNA was extracted. The expression of $\mathrm{C}$-fos (A) and $\mathrm{c}$-jun (B) mRNA were analyzed by RT-PCR as described in the Methods. Densitometric analysis represented the ratio of the c-fos or $\mathrm{c}$-jun gene to the constitutive gene. GAPDH was used for a marker of equal loading. The density of the bands was quantified by the NIH Image program. Values presented are expressed as mean \pm SEM $(n=4)$. ${ }^{*}, P<0.01$ compared with their respective controls. 
Ott et al., 2000), we evaluated the role of MAPK signal pathways on the $\left[{ }^{3} \mathrm{H}\right]$ thymidine incorporation, which was increased by Ang II in the VSMC. Ang II dramatically increased the phosphorylation of ERK $1 / 2$, JNK1/2 and p38 (Figure 2 A-C). The phosphorylation of ERK 1/2, JNK1/2, and p38 peaked at 5-10 min after Ang II treatment and gradually decreaseed over time. Since c-jun and c-fos are AP-1 transcription factors which play an important role in the MAPK signaling pathway (Graham and Gilman, 1991; Chen et al., 1996), we determined the expression of c-jun and c-fos mRNA. The c-jun and $c$-fos mRNA expressions increased within 15 minutes after Ang II treatment (Figure 3). The increased mRNA levels in c-jun and c-fos gradually declined over time. It indicates that Ang II may regulate $\left[{ }^{3} \mathrm{H}\right]$ thymidine incorporation by transcriptional levels.

In order to confirm that MAPK signal pathway is responsible for the VSMC proliferation, we examined the effect of U0126 for an inhibition of MEK, SP600125 for an inhibition of JNK, or SB203580 for

A
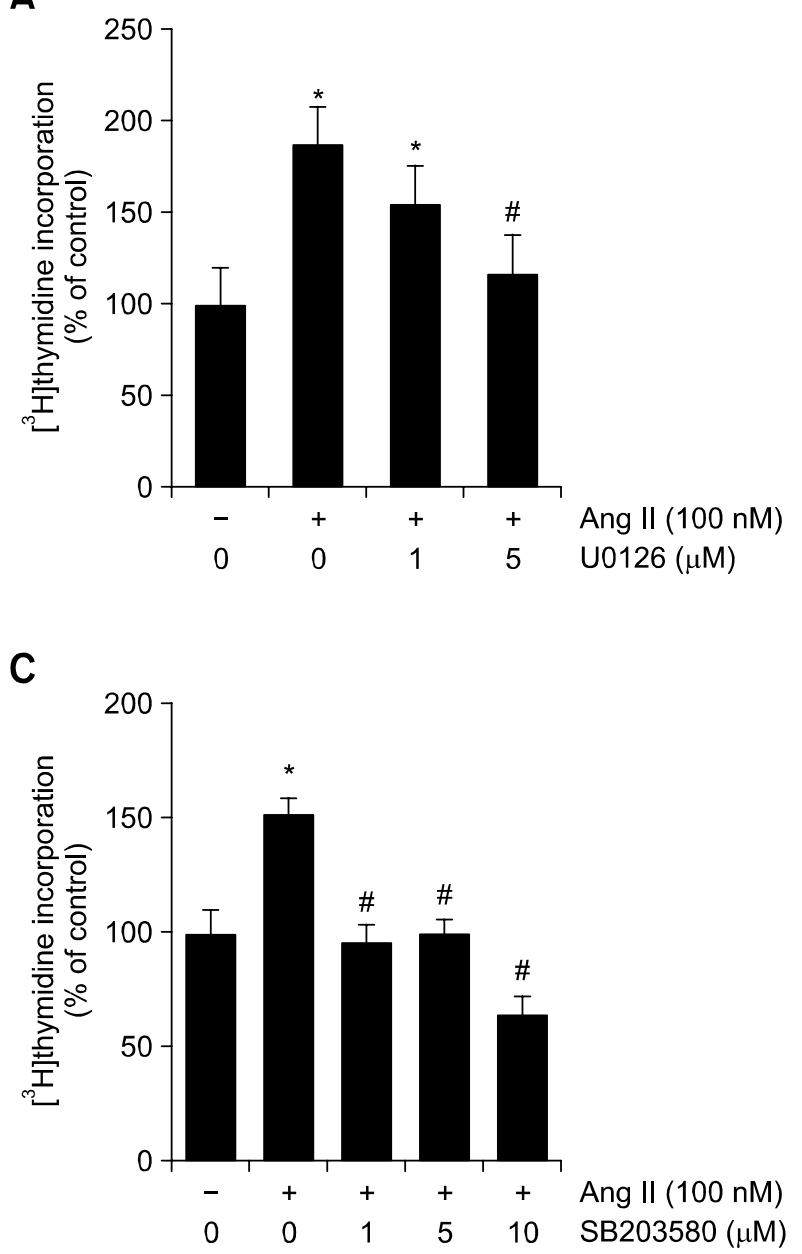

an inhibition of a p38 kinase, on the Ang IIstimulated incorporation of $\left[{ }^{3} \mathrm{H}\right]$ thymidine into the VSMC. U0126 (Figure 4A), SP600125 (Figure 4B) or SB203580 (Figure 4C) prevented the Ang II-stimulated incorporation of $\left[{ }^{3} \mathrm{H}\right]$ thymidine into the VSMC. The inhibitory effect of SB203580 was stronger than U0126 or SP600125.

\section{Effect of EGCG on the Ang II-induced phosphorylation of MAPK, and mRNA expression of $\mathrm{c}$-fos and $\mathrm{c}$-jun in the VSMC}

To determine whether the inhibitory effect of catechins on the Ang II-induced $\left[{ }^{3} \mathrm{H}\right]$ thymidine incorporation is associated with the MAPK signaling pathways, we examined the effect of EGCG on the Ang II-activated MAPK/c-jun or c-fos signal pathways. We used EGCG because it is a major catechin derived from green tea and it exerts a strong inhibitory effect on the Ang II-mediated increased $\left[{ }^{3} \mathrm{H}\right]$ thymidine incorporation. EGCG inhibited the phosphorylation of ERK 1/2, JNK $1 / 2$ and

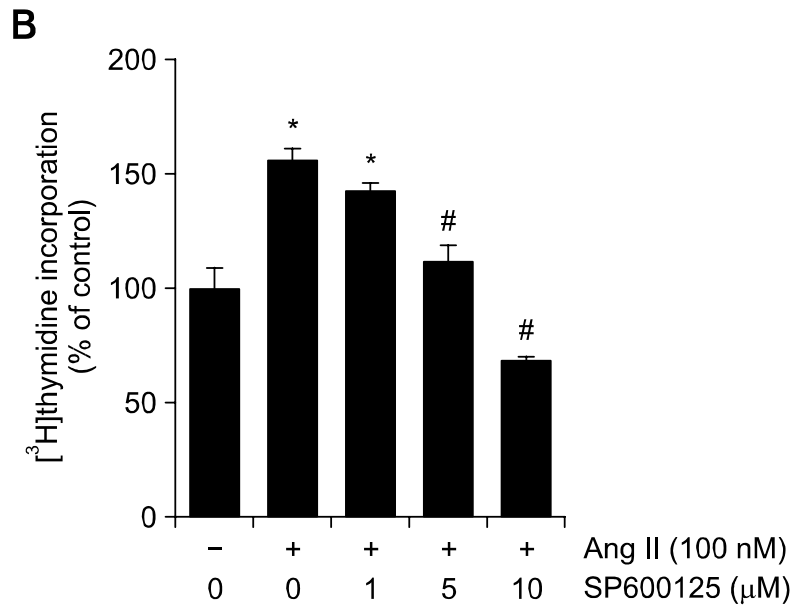

Figure 4. Effect of the inhibition of MEK (A), JNK 1/2 (B) and p38 (C) on angiotensin II (Ang II)-induced $\left.{ }^{3} \mathrm{H}\right]$ thymidine incorporation into primary cultured aortic vascular smooth muscle cells (VSMC). The VSMCs were cultured in a $10 \%$ FBS in DMEM. Forty-eight $h$ before using the experiments the cells were incubated in a $0.5 \%$ FBS in DMEM. In order to determine DNA synthesis, cells were treated with $1 \mu \mathrm{Ci}$ of $\left[^{3} \mathrm{H}\right]$ thymidine for $4 \mathrm{~h}$ and then harvested to measure radioactivity using a $\beta$-counter. Some cells were treated with either a vehicle or $100 \mathrm{nM}$ of Ang $\| 20 \mathrm{~h}$ before the treatment of $1 \mu \mathrm{Ci}$ of $\left[^{3} \mathrm{H}\right]$ thymidine. Some cells were treated with (A) U0126, an inhibitor of MEK, (B) SP600125, an inhibitor of JNK $1 / 2$, or (C) SB203580, an inhibitor of p38 MAPK, at indicated concentrations of EGCG 30 min before treatment with $100 \mathrm{nM}$ of Ang II. Data represent the percentage of $\left.{ }^{3} \mathrm{H}\right]$ thymidine incorporation in the absence of Ang II and MAPK inhibitors. Experiments were performed in triplicate or quadruplicate with the VSMC. Values are means \pm SEM. ${ }^{*}, P<$ 0.01 compared with the absence of EGCG and Ang II. ${ }^{\#}, P<0.01$ compared with the absence of EGCG and the presence of Ang II. 
A

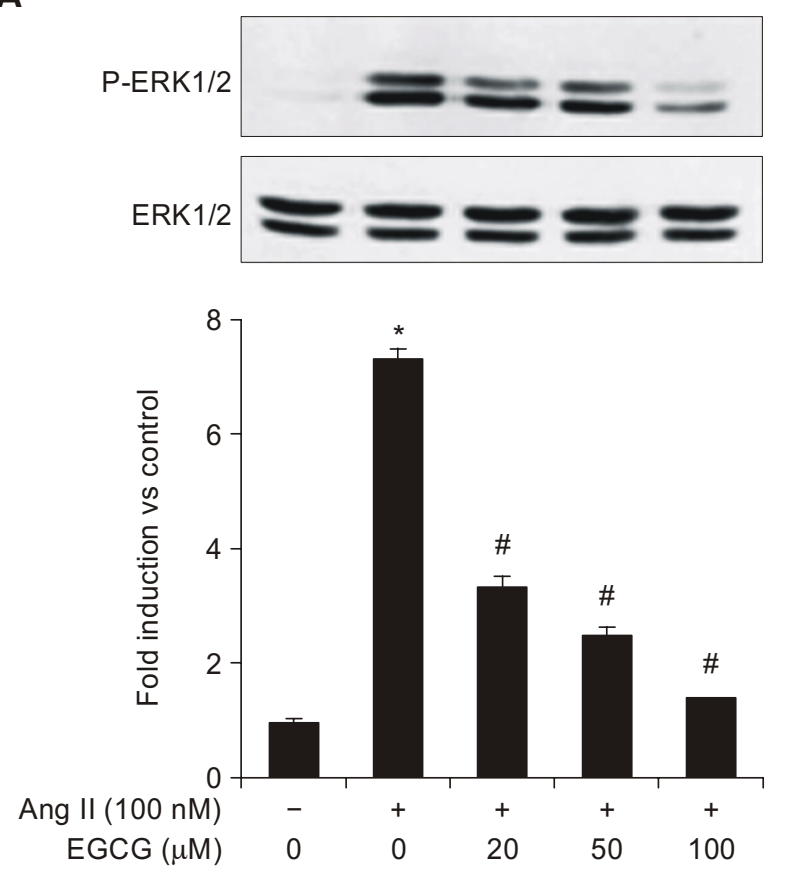

C
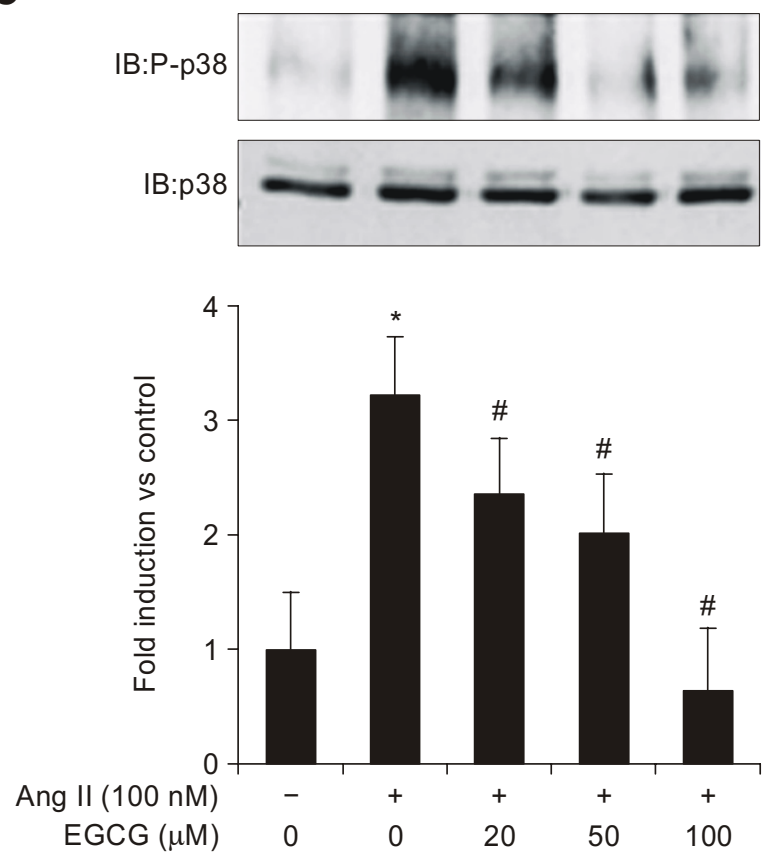

p38 stimulated by Ang II (Figure 5A-C). EGCG also inhibited the Ang II-stimulated expression of c-jun or c-fos mRNA (Figure 6).

\section{Discussion}

B
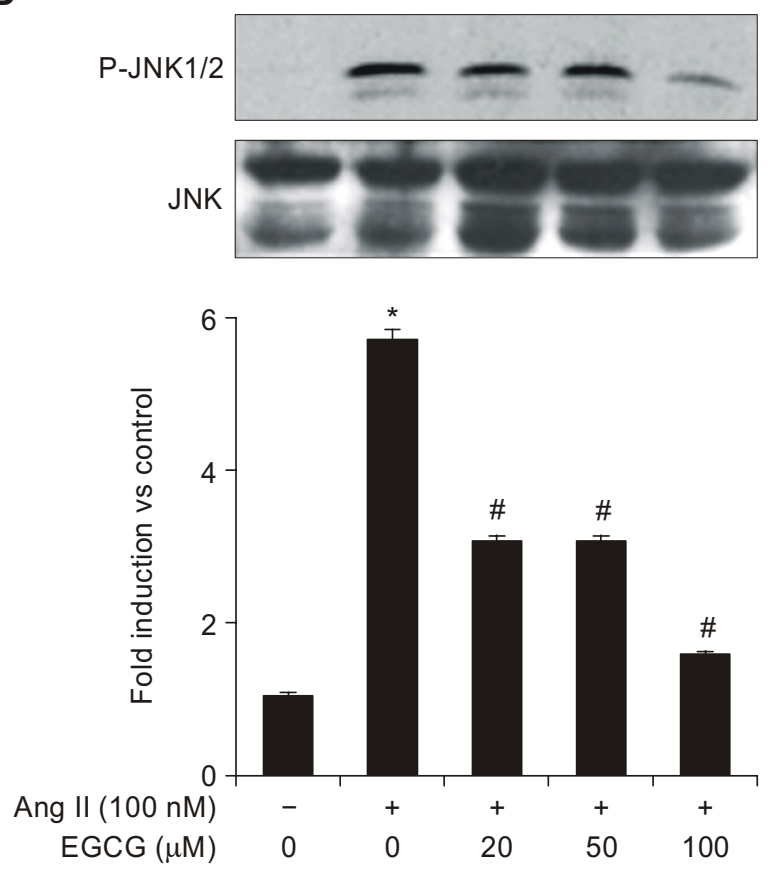

Figure 5. Effect of the epigallocatechin-3-gallate (EGCG) on the angiotensin II (Ang II)-stimulated phosphorylation of ERK1/2 (A), JNK1/2 (B) and p38 (C) in the primary cultured vascular smooth muscle cells (VSMC). The VSMCs were cultured in a 10\% FBS in DMEM. Forty-eight $\mathrm{h}$ before using the experiments the cells were incubated in a $0.5 \%$ FBS in DMEM. Some cells were pretreated with either vehicle or EGCG in the indicated concentrations 30 min before treatment of either vehicle or $100 \mathrm{nM}$ of Ang II for $10 \mathrm{~min}$. The phosphorylation of ERK1/2 (A), JNK1/2 (B), and p38 (C) was determined as described in the Material and Methods. The density of the bands was quantified by the NIH Image program. Values presented are expressed as mean \pm SEM $(n=4)$. ${ }^{*}, P$ $<0.01$ compared with the absence of EGCG and Ang II. ${ }^{\#}, P<0.01$ compared with the absence of EGCG and the presence of Ang II.

The present study demonstrates that the catechins in green tea inhibit growth-promoting effects of Ang II and that the inhibitory effect of catechins is associated with the MAPK signal pathways in the primary cultured VSMC. In addition, it demonstrates that catechins at a high concentration inhibit the DNA synthesis in the absence of Ang II. 
A
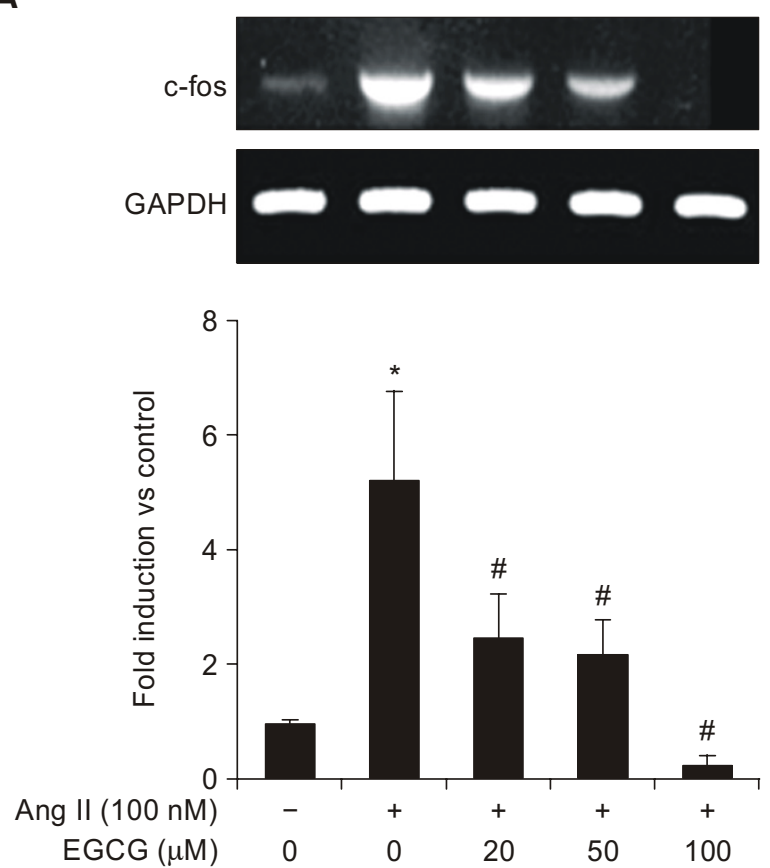

B
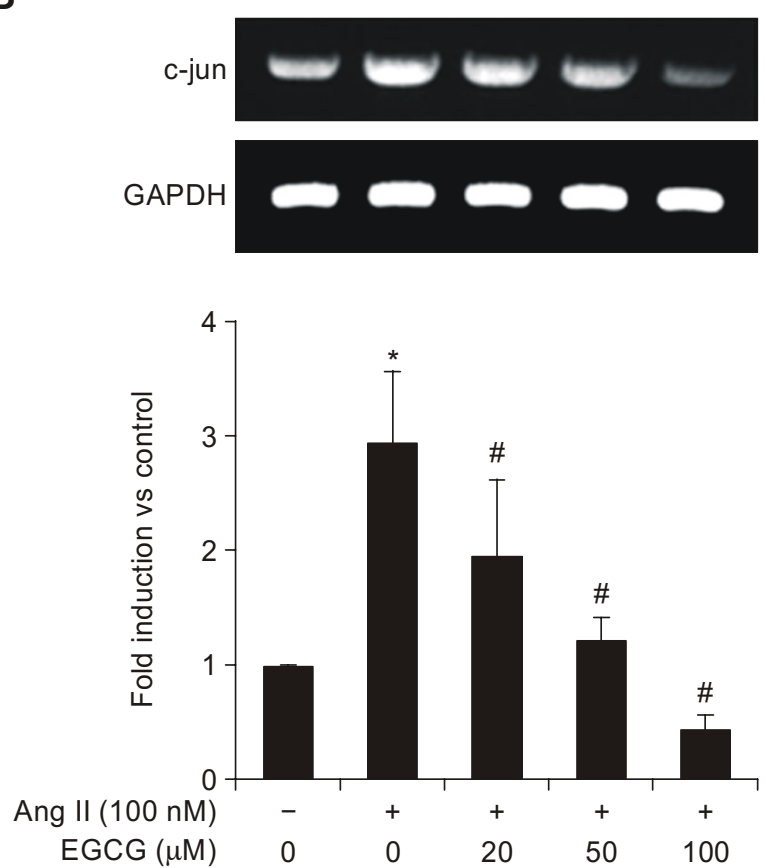

Figure 6. Effect of the epigallocatechin-3-gallate (EGCG) on angiotensin II (Ang II)-induced expression of mRNA of c-fos (A) and c-jun (B) in the primary cultured vascular smooth muscle cells (VSMC). The VSMCs were cultured in a 10\% FBS in DMEM. Forty-eight $h$ before using the experiments the cells were incubated in a $0.5 \%$ FBS in DMEM. The VSMCs were pretreated with EGCG at the indicated concentrations for 30 min before treatment with $100 \mathrm{nM}$ of Ang II for $30 \mathrm{~min}$. The expressions of c-fos (A) and c-jun (B) mRNA were analyzed by RT-PCR as described in the Materials and Methods. Densitometric analysis represented the ratio of the c-fos or $\mathrm{c}$-jun gene to the constitutive gene. GAPDH was used for a marker of equal loading. The density of the bands was quantified by the NIH Image program. Values presented are expressed as mean \pm SEM $(n=4)$. ${ }^{*}, P<0.01$ compared with the absence of EGCG and Ang II. \#, $P<0.01$ compared with the absence of EGCG and the presence of Ang II.

An intake of green tea reduced the incidence of cardiovascular disease in human (Vinson et al., 2004). Ang II is produced locally in the vascular wall and cultured VSMC (Dzau et al., 1983), and stimulates VSMC proliferation, which is a characteristic feature of vascular-related diseases such as atherosclerosis (Campbell-Boswell and Robertson, 1981; Geisterfer and Owens, 1989; Newby and George, 1993). Overproduction of Ang II accelerates the development of abnormal vascular wall thickening and atherosclerotic lesions in the vessels (Campbell-Boswell and Robertson, 1981; Geisterfer and Owens, 1989; Newby and George, 1993). In the present studies the green tea catechins inhibit the Ang II-induced increase of DNA synthesis in VSMCs. The inhibitory effect of catechins on the growth promoting effects of Ang II was ECG > EGCG > EC > catechin at $50 \mu \mathrm{M}$ of catechins and $E C>E G C G>E C G$ or catechin at $20 \mu \mathrm{M}$. Our result is the first describing that the isoforms of catechins exert different anti-proliferative effects on VSMC.

Recent studies have demonstrated the anti-proliferative effect of EGCG in VSMC stimulated with basic fibroblast growth factor (bFGF) (Hwang et al., 2002) and platelet-derived growth factor (Sachinidis et al., 2002; Weber et al., 2004). In contrast, Zheng and colleagues (2004) reported that, in Ang II-stimulated VSMC, EGCG inhibited hypertrophy as measured by $\left[{ }^{3} \mathrm{H}\right]$ leucine incorporation, but did not influence the cell number of rat aortic VSMC. In the present studies, however, we find that EGCG inhibits the Ang II-stimulated VSMC proliferation. The discrepancy between the results of Zheng and colleagues (2004) and ours may be due, at least in part, to different cell culture conditions and the origin of the primary cultured rat aortic VSMC. Zheng and colleagues used male rats to generate the VSMC, whereas we used female rats. Gender differences in cardiovascular diseases are well-known (Patel et al., 2004). Recently, we have demonstrated that gender differences in the susceptibility on kidney ischemia/ reperfusion injury and the post-ischemic phosphorylation of MAPKs (Park et al., 2004).

At least three distinct members of the MAPK family are expressed in mammalian cells: ERKs, JNKs, and p38 proteins. ERKs are activated by growth factors and are involved in both cell proli- 
feration and differentiation, whereas JNKs and p38 proteins are activated in response to proinflammatory cytokines and environmental stress (Sohn et al., 2001). Ang II activates the MAPK family (Eguchi et al., 1996), and stimulates cell proliferation via the activator protein-1 (AP-1) complex by the induction of proto-oncogene expression such as c-fos and c-jun, which constitute the AP-1 (Graham and Gilman, 1991; Chen et al., 1996). We therefore investigated whether the anti-proliferative effect of catechins is involved in the phosphorylation of the MAPK family and expression of the proto-oncogenes. In the present study, we found that EGCG significantly inhibited the Ang II-induced phosphorylation of ERK 1/2, JNK $1 / 2$ and p38 in VSMC. Specific inhibitors of MAPKs prevented the Ang II-induced DNA synthesis. In addition, EGCG inhibited the Ang II-induced gene expression of transcription factors of MAPKs such as c-jun and c-fos. The present results suggest that the inhibitory effect of catechins on VSMC proliferation is associated with suppression of MAPK and AP-1 activation. Recently, we also observed that matairesinol, a kind of phenolic compounds, exerted the same inhibitory effects as catechins on proliferation and phosphorylation of ERK 1/2, JNK $1 / 2$ and p38 in VSMC. Several other evidences have suggested that EGCG inhibited MAPKs activity to regulate diverse cellular responses in different cell types. EGCG suppressed phosphorylation of ERK $1 / 2$ in the 3-L1 preadipocytes (Hung et al., 2005), and that of ERK and JNK in human gastric cancer AGS cells (Kim et al., 2004). EGCG inhibited JNK activity in bFGF-stimulated VSMC (Hwang et al., 2002).

In conclusion, the inhibitory effect of catechins on the Ang II-stimulated DNA synthesis in VSMC is associated at least partly with suppression of MAPK and AP-1 signaling pathways. The observation may explain the beneficial effects of green tea in cardiovascular diseases and it will be useful to develop prevention and therapeutics of cardiovascular diseases.

\section{Acknowledgment}

This work was supported by a research grant from the Korea Research Foundation (R05-2004-00011561-0, KRF: E00032).

\section{References}

Berk BC, Vekshtein V, Gordon HM, Tsuda T. Angiotensin II-stimulated protein synthesis in cultured vascular smooth muscle cells. Hypertension 1989;13:305-14

Campbell-Boswell M, Robertson AL Jr. Effects of angiotensin II and vasopressin on human smooth muscle cells in vitro. Exp
Mol Pathol 1981;35:265-76

Cao Y, Cao R. Angiogenesis inhibited by drinking tea. Nature 1999;398:381

Chen RH, Juo PC, Curran T, Blenis J. Phosphorylation of c-Fos at the C-terminus enhances its transforming activity. Oncogene 1996;12:1493-502

Davis RJ. The mitogen-activated protein kinase signal transduction pathway. J Biol Chem 1993;268:14553-6

Duff JL, Berk BC. Angiotensin II-mediated signal transduction events in vascular smooth muscle cells: kinases and phosphatases. Blood press Suppl 1995;2:55-60

Dzau VJ, Hollenberg NK, Williams GH. Neurohumoral mechanisms in heart failure: role in pathogenesis, therapy, and drug tolerance. Fed Proc 1983;42:3162-9

Eguchi S, Matsumoto T, Motley ED, Utsunomiya H, Inagami $T$. Identification of an essential signaling cascade for mitogen-activated protein kinase activation by angiotensin II in cultured rat vascular smooth muscle cells. Possible requirement of $\mathrm{Gq}$-mediated p21ras activation coupled to a $\mathrm{Ca}^{2+} /$ calmodulin-sensitive tyrosine kinase. J Biol Chem 1996;271:14169-75

Geisterfer AA, Owens GK. Arginine vasopressin-induced hypertrophy of cultured rat aortic smooth muscle cells. Hypertension 1989;14:413-20

Graham R, Gilman M. Distinct protein targets for signals acting at the c-fos serum response element. Science 1991;251: $189-92$

Horiuchi M, Akishita M, Dzau VJ. Recent progress in angiotensin II type 2 receptor research in the cardiovascular system. Hypertension 1999;33:613-21

Huang C, Rajfur Z, Borchers C, Schaller MD, Jacobson K. JNK phosphorylates paxillin and regulates cell migration. Nature 2003;424:219-23

Hung PF, Wu BT, Chen HC, Chen YH, Chen CL, Wu MH, Liu $\mathrm{HC}$, Lee MJ, Kao YH. The antimitogenic effect of green tea (-)-epigallocatechin gallate on 3T3-L1 preadipocytes depends on the Erk and Cdk2 pathways. Am J Physiol Cell Physiol 2005;288:C1094-108

Hwang KC, Lee KH, Jang Y, Yun YP, Chung KH. Epigallocatechin-3-gallate inhibits basic fibroblast growth factorinduced intracellular signaling transduction pathway in rat aortic smooth muscle cells. J Cardiovasc Pharmacol 2002;39: 271-7

Ikigai H, Nakae T, Hara Y, Shimamura T. Bactericidal catechins damage the lipid bilayer. Biochim Biophys Acta 1993;1147: $132-6$

Jackson CL, Schwartz SM. Pharmacology of smooth muscle cell replication. Hypertension 1992;20:713-36

Kim HS, Kim MH, Jeong M, Hwang YS, Lim SH, Shin BA, Ahn BW, Jung YD. EGCG blocks tumor promoter-induced MMP-9 expression via suppression of MAPK and AP-1 activation in human gastric AGS cells. Anticancer Res 2004;24:747-53

Kim TI. Matairesinol inhibits angiotensin II-induced VSMC proliferation through MAPK and Akt/PKB signaling pathways. 
2004; Ph.D. Thesis, Kyungpook National University, Korea

Lake AC, Castellot JJ Jr. CCN5 modulates the antiproliferative effect of heparin and regulates cell motility in vascular smooth muscle cells. Cell Commun Signal 2003;1:5

Newby AC, George SJ. Proposed roles for growth factors in mediating smooth muscle proliferation in vascular pathologies. Cardiovasc Res 1993;27:1173-83

Park KM, Kim JI, Ahn Y, Bonventre AJ, Bonventre JV. Testosterone is responsible for enhanced susceptibility of males to ischemic renal injury. J Biol Chem 2004;279: 52282-92

Patel H, Rosengren A, Ekman I. Symptoms in acute coronary syndromes: does sex make a difference? Am Heart $\mathrm{J}$ 2004;148:27-33

Ross R. The pathogenesis of atherosclerosis: a perspective for the 1990s. Nature 1993;362: 801-9

Sachinidis A, Skach RA, Seul C, Ko Y, Hescheler J, Ahn HY, Fingerle J. Inhibition of the PDGF beta-receptor tyrosine phosphorylation and its downstream intracellular signal transduction pathway in rat and human vascular smooth muscle cells by different catechins. Faseb J 2002;16:893-5

Schmidt-Ott KM, Kagiyama S, Phillips MI. The multiple actions of angiotensin II in atherosclerosis. Regul Pept 2000;93:65-77

Sohn YD, Lim HJ, Hwang KC, Kwon JH, Park HY, Chung KH, Cho SY, Jang Y. A novel recombinant basic fibroblast growth factor and its secretion. Biochem Biophys Res Commun 2001;284:931-6

Tso JY, Sun WH, Kao TH, Reece KS, Wu R. Isolation and characterization of rat and human glyceraldehyde-3-phosphate dehydrogenase cDNAs: Genomic complexity and molecular evolution of the gene. Nucleic Acids Res 1985;13:
2485-502

Uchida S, Ozaki M, Akashi T, Yamashita K, Niwa M, Taniyama K. Effects of (-)-epigallocatechin-3-O-gallate (green tea tannin) on the life span of stroke-prone spontaneously hypertensive rats. Clin Exp Pharmacol Physiol 1995;22: S302-3

Vinson JA, Teufel K, Wu N. Green and black teas inhibit atherosclerosis by lipid, antioxidant, and fibrinolytic mechanisms. J Agric Food Chem 2004;52:3661-5

Weber AA, Neuhaus T, Skach RA, Hescheler J, Ahn HY, Schror $\mathrm{K}, \mathrm{Ko} \mathrm{Y}$, Sachinidis A. Mechanisms of the inhibitory effects of epigallocatechin-3 gallate on platelet-derived growth factor-BB-induced cell signaling and mitogenesis. FASEB $\mathrm{J}$ 2004; $18: 128-30$

Weisburger JH, Chung FL. Mechanisms of chronic disease causation by nutritional factors and tobacco products and their prevention by tea polyphenols. Food Chem Toxicol 2002;40: $1145-54$

Yamaguchi $Y$, Hayashi M, Yamazoe H, Kunitomo M. Preventive effects of green tea extract on lipid abnormalities in serum, liver and aorta of mice fed a atherogenic diet. Nippon Yakurigaku Zasshi 1991;97:329-37

Yokozawa T, Oura H, Nakagawa H, Sakanaka S, Kim M. Effects of a component of green tea on the proliferation of vascular smooth muscle cells. Biosci Biotechnol Biochem 1995;59:2134-6

Zheng Y, Song HJ, Kim CH, Kim HS, Kim EG, Sachinidis A, Ahn HY. Inhibitory effect of epigallocatechin 3-O-gallate on vascular smooth muscle cell hypertrophy induced by angiotensin II. J Cardiovasc Pharmacol 2004;43:200-8 